\title{
Revus
}

Journal for Constitutional Theory and Philosophy of

Law / Revija za ustavno teorijo in filozofijo prava

34 | 2018

Norms and Legal Normativity

\section{La filosofía del Derecho como filosofía práctica}

Jesús Vega

URL: http://journals.openedition.org/revus/3990

DOI: 10.4000/revus.3990

ISSN: 1855-7112

Editor

Klub Revus

Edición impresa

Fecha de publicación: 10 junio 2018

ISSN: 1581-7652

Referencia electrónica

Jesús Vega, «La filosofía del Derecho como filosofía práctica », Revus [Online], 34 | 2018, Online since 29 December 2017, connection on 13 December 2018. URL : http://journals.openedition.org/ revus/3990 ; DOI : 10.4000/revus.3990

Este documento fue generado automáticamente el 13 diciembre 2018.

All rights reserved 


\title{
La filosofía del Derecho como filosofía práctica
}

\author{
Jesús Vega
}

\section{Introducción}

1 Quienquiera que se aproxime al problema del status de la "Filosofía del Derecho" como disciplina filosófica ha de encarar un conjunto de problemas sumamente intrincados. En primer lugar, el problema de explicar por qué su institucionalización como tal disciplina es característicamente moderna: la Philosophie des positiven Rechts de Hugo (1798), la Philosophy of Positive Law de Austin (1861), la Philosophie des Rechts de Hegel (1821), ¿eran realmente una nueva disciplina o sólo un nuevo nombre para una reflexión filosófica que ya era muy antigua y tradicional? Este problema tiene que ver con la valoración filosófica del Derecho natural.

2 En segundo lugar, el problema de las consabidas bifurcaciones históricas y temáticas de nuestra disciplina: por un lado, la bifurcación resultante de la oposición "Filosofía del Derecho de los juristas" versus "Filosofía del Derecho de los filósofos" (Bobbio, 1990) y, por otro, la bifurcación resultante de la oposición "Filosofía del Derecho" versus "Teoría del Derecho". Este problema tiene que ver con la valoración filosófica del positivismo jurídico.

3 En este trabajo voy a centrarme fundamentalmente en el segundo de esos problemas. Mi propósito es hacer una vindicación de la naturaleza estrictamente filosófica de nuestra disciplina. Ello exige en primer lugar tomar posición previa sobre la cuestión de qué es en general la filosofía, fijar unas premisas mínimas para la definición de la racionalidad filosófica y establecer una clasificación metateórica de los géneros del discurso filosófico (2). Esto me llevará, a continuación, a hacer un examen crítico de la dicotomía de Bobbio entre filosofía jurídica de juristas y de filósofos (3). En tercer lugar, es necesario abordar la difícil cuestión de reformular las relaciones existentes entre la filosofía jurídica como disciplina "especial", "sectorial", "aplicada" o "regional" y la filosofía "general" (o "pura", “fundamental”, “esencial”, etc.). Aquí confluye el problema genérico de cuáles 
son las "partes" de la filosofía entendida como tal disciplina general (lógica, epistemología, ética, antropología, filosofía natural, etc., siendo así que ellas mismas son vistas muchas veces también como filosofías "especiales") con el problema específico ofrecido, además, por una disciplina filosófica que está explícitamente "centrada" en torno a una institución particular ligada a conceptos propios, como es el Derecho (un caso comparable al de otras "filosofías-de": filosofía de la religión, filosofía del arte, de la historia, etc.). Replantearé este problema a partir de la distinción entre conceptos del Derecho e ideas del Derecho (4). En cuarto lugar, voy a defender la tesis de que lo decisivo a la hora de entender qué tipo de filosofía es -o debe ser- la filosofía del Derecho no es tanto (o no sólo) la relación que hay entre ella y la filosofía en general cuanto, sobre todo, la relación que hay entre ella y el propio Derecho (5). Es el tipo de práctica que el Derecho representa lo que convierte en necesaria su vinculación interna e ineludible con ideas y concepciones de naturaleza filosófica. Esta visión práctica del Derecho, expresiones diferentes de la cual pueden encontrarse en autores contemporáneos de gran relevancia que de distintos modos se han situado más allá de la dicotomía iuspositivismoiusnaturalismo (como Nino, Alexy, Dworkin, Atienza), sería entonces - tal es la tesis que sostengo- íntimamente solidaria de una visión de la filosofía jurídica como filosofía práctica (6). El rasgo esencial que considero unido a tal condición -la de constituir un tipo de "filosofía práctica"- es la centralidad y preeminencia que en ella adquiere la dimensión valorativa, el concepto del valor. Las ideas fundamentales de la filosofía del Derecho serían los valores prácticos mismos entendidos como ideas prácticas. De ahí la conexión necesaria del discurso iusfilosófico con la propia práctica jurídica. Lo que otorga a la filosofía jurídica un lugar especial (incluso una suerte de "primado") dentro del espacio general de la filosofía práctica es la perspectiva privilegiada que posee respecto de los valores prácticos fundamentales (esto es, los valores morales y políticos) en razón de su proximidad con la práctica del Derecho, siendo el Derecho aquella institución que consiste precisamente en reconciliar el conflicto y recomponer la unidad de esos valores en términos justificativos y argumentativos. Este planteamiento lleva a la superación de la dicotomía entre el iusnaturalismo (cuya seña distintiva es la afirmación de los valores como fundamentos últimos del Derecho, pero en clave dogmática o metafísica, anegando la filosofía jurídica en un discurso iusmoralista) y el positivismo jurídico (cuya seña distintiva es la distancia y neutralidad valorativa frente al Derecho, pero en clave escéptica o relativista postulando más un discurso técnico-científico del Derecho que estrictamente filosófico).

\section{Una concepción general de la filosofía}

4 Asumiré la visión de la filosofía del Derecho como "totalización racional y crítica del fenómeno jurídico" sostenida por M. Atienza. ${ }^{1}$ La clave de esta concepción (que proviene del filósofo español Gustavo Bueno) ${ }^{2}$ estriba en la diferenciación entre conceptos e ideas. Los conceptos serían propios de las ciencias (en un sentido amplio, comprensivo de las técnicas), mientras que las ideas serían la materia propia de la filosofía. Ambos conceptos científicos e ideas filosóficas- constituirían "totalizaciones críticas" (la "crítica" no es privativa de la filosofía) y ambos envuelven universalidad. Pero el tipo de totalización y de universalidad de las ideas es diferente e irreductible al de los conceptos. Los problemas filosóficos responden a un formato propio: no son problemas técnicos o científicos, sino problemas que surgen a partir o con ocasión de éstos, en un segundo 
grado de reflexión. La filosofía no es un saber originario o de "primer grado", pero tiene una justificación autónoma como saber diferenciado, sustantivo, no pudiendo ser reducido ni a un simple saber "adjetivo" (destinado a ser "liquidado" por las ciencias) ni "genitivo" (confinado a un simple análisis lógico o síntesis enciclopédica en relación con el saber científico), ni tampoco, por supuesto, un saber "dogmático" (desconectado de las ciencias o "metafísico").

Las ciencias, sin duda, constituyen el exponente del saber más universal del que disponemos. Sin embargo, la suya sería una universalidad restringida o acotada a ciertos dominios conceptuales (o "universos de discurso") más o menos cerrados en función de teorías y leyes objetivas, dominios a los que Bueno, siguiendo una denominación tradicional, llama "categorías": las categorías físicas, químicas, matemáticas, antropológicas, sociológicas, psicológicas, etc. Los conceptos científicos (incluyendo las técnicas y las tecnologías) serían universales relativamente a -o dentro de - cada uno de estos dominios categoriales, segregando todo aquello que resulte conceptualmente impertinente - "externo"- a ellos. Pero por ello mismo no agotarían todo lo que puede ser dicho racionalmente ni respecto a cada categoría ni sobre el conjunto de todas ellas (es decir, sobre la conceptualización del mundo). De modo que al menos cuestiones tales como las relaciones que hay entre esas diversas categorías (cuántas ciencias hay y en qué se diferencian), su alcance (hasta dónde llega la universalidad de cada ciencia) o su validez (qué significa considerar universalmente fundado un conocimiento científico) serían problemas que ya no pueden ser resueltos desde el interior de las categorías mismas: pues no son problemas científicos o técnicos, analizables en los términos de sus propios instrumentos conceptuales. Por el contrario, exigen un diferente tratamiento racional, una totalización de otro orden, también de carácter universalista, y este es precisamente el discurso filosófico. Habría, pues, otro género de conceptos "de segundo orden", cuya universalidad es transversal a los conceptos categoriales e irreductible a ellos. Serian conceptos trascendentales, por cuanto "trascienden" a cada una de las categorías, pero no a todas en su conjunto (como sucedía con las tres ideas clásicas de la metafísica tradicional arrumbadas por Kant en la primera Crítica). ${ }^{3} \mathrm{~A}$ estos conceptos cabe llamarlos en efecto ideas filosóficas, siguiendo de nuevo una tradición que arranca de Platón y llega hasta Kant o Hegel, sin que ello suponga comprometerse con la concepción metafísica tradicional, sino entendiéndolas ahora como ideas en sentido históricocultural (vinculadas a "ideologías", pero no reducibles a éstas). Las teorías filosóficas no son entonces otra cosa que elaboraciones e interpretaciones más o menos sistemáticas de estas ideas a lo largo de su curso histórico. Responden por tanto a problemas suscitados recurrentemente por los conceptos de las ciencias que, sin embargo, se resisten a ser asimilados o reducidos a simples problemas científicos o técnicos. En la medida en que involucran ideas y no sólo conceptos, los problemas filosóficos tienen un formato genuinamente propio. No son resueltos por las ciencias o técnicas, sino más bien replanteados por éstas (y de ahí su persistencia histórica). Un problema filosófico se caracteriza ante todo por el hecho de que cuestiona peculiarmente toda una categoría en su conjunto, al ponerla en conexión con otras e indagar acerca de sus fundamentos y su validez. Eso es lo que sucede, por ejemplo, con las preguntas de tipo epistemológico y ontológico. Éstas suscitan cómo las categorías representan o conceptualizan el mundo y cómo el mundo es representado o conceptualizado por ellas. La respuesta a ello exige un tipo de reflexión totalizadora que envuelve la crítica -es decir, el análisis, la comparación, la clasificación, el establecimiento de límites- de los conceptos científicos entre sí con 
arreglo a concepciones generales más o menos sistemáticas que manejan ideas epistemológicas (una cierta teoría de la ciencia o del conocimiento) y ontológicas (una cierta teoría de los elementos constituyentes de lo real).

6 Ahora bien: ¿cómo se traduce en relación con el Derecho tal "totalización crítica" a la hora de definir la filosofía jurídica? Por un lado, hay que precisar el sentido que tiene esa noción de "totalización". Por otro, hay que poder dar un contenido preciso a ese tópico del carácter "crítico" de la filosofía del Derecho.

7 Respecto a lo primero, Atienza vincula el significado de esa totalización específicamente con el carácter trascendental o intercategorial de la iusfilosofía. Así, señala que "la función esencial de los filósofos del Derecho tendría que ser la de actuar como «intermediarios» entre los saberes y prácticas jurídicas, por un lado, y el resto de las prácticas y saberes sociales -incluida la filosofía-, por el otro. [...] su lugar está, precisamente, en las fricciones y en los vacíos que se producen en el funcionamiento de los mismos. Por eso, la filosofía del Derecho puede tener la pretensión de ser un saber totalizador, en la medida en que su punto de partida y de llegada sean esos otros saberes y prácticas" (Atienza 2015: 5).

8 Respecto a lo segundo, la dimensión crítica de la filosofía jurídica, Atienza asume que este rasgo deriva de que la iusfilosofía reflexiona "desde una perspectiva que no coincide con la de quienes se sitúan en el interior de cada una de esas parcelas, pues el filósofo del Derecho puede y debe cuestionar los marcos establecidos, lo cual [...] le está vedado al que opera exclusivamente desde el interior de una determinada ciencia o técnica (que, naturalmente, no renuncia a la crítica, sino que la ejerce de una manera distinta)" (ibid.).

Ambos rasgos, como se ve, son sustancialmente coincidentes. $\mathrm{Y}$ ambos conducen a plantear un mismo problema: ¿cómo es posible que la filosofía del Derecho, hallándose "centrada" en una única categoría, sea genuinamente "filosófica", es decir, constituya un discurso totalizador-critico (trascendental o intercategorial)? Dicho de otro modo: si lo que hace de la filosofía jurídica un discurso propio y específico es su carácter "intermediario" o "transversal" en relación con las diferentes conceptualizaciones del fenómeno jurídico -tanto internas a la categoría jurídica como externas-, ¿cómo puede seguir siendo una filosofía "regional", en el doble sentido de ser una filosofía diferenciada de la filosofía "general" y, además, de carácter "local" o "particular" (esto es, vinculada al propio discurso jurídico, que es un discurso de implantación evidentemente local y particular? ¿Cómo se compatibilizan ambas cosas: su carácter "genitivo" jurídico y su dimensión universal o "trascendental" filosófica?

\section{Filosofía del Derecho de juristas y de filósofos}

Esto nos lleva a un problema conexo -conocidamente planteado por Bobbio-que es el de la dualidad polémica entre filosofía del Derecho de juristas y de filósofos. Un problema que arranca del hecho de que la tradición del pensamiento filosófico occidental sobre el Derecho ha sido desarrollada históricamente en forma "bifurcada": por filósofos que llegan al Derecho desde sus sistemas omnicomprensivos de ideas para encajarlo dentro de ellos y por juristas que recurren de distintas formas a ciertos marcos filosóficos generales para construir teorías también omnicomprensivas pero de alcance esencialmente endojurídico o enfocadas esencialmente a la reflexión y elaboración de las propias categorías y conceptos jurídicos. Bifurcación que podemos ilustrar rápidamente mediante el contraste, en la época antigua, entre Aristóteles y Cicerón, en la época medieval, entre 
Agustín y Graciano o Tomás de Aquino y Bártolo, y en la época moderna entre el "iusnaturalismo de los filósofos" (Suárez, Leibniz) y el "iusnaturalismo de los juristas" (Grocio, Thomasius). Desde que, en la época contemporánea, surge la filosofía del Derecho como disciplina de nuevo cuño - pero en sustitución del "Derecho natural", que ya era naturalmente una iusfilosofía - ésta ha sido cultivada de forma casi exclusiva en las facultades jurídicas y no en las facultades de filosofía: es decir, por juristas. Lo cual, unido a la especialización académica, ha incrementado el sesgo endogámico de la iusfilosofía (así como el aislamiento de la filosofía general respecto del "huerto cerrado" del Derecho, en palabras del propio Bobbio). Pero lo cierto es que los juristas-filósofos han seguido echando mano de filosofías generales vigentes o no tan vigentes (así, no se entendería a Kelsen sin Kant, a Hart sin Wittgenstein, a Finnis sin Tomás de Aquino, a Alexy sin Habermas, a los hermenéuticos sin Gadamer), filosofías a las cuales sin embargo dan giros diferentes y novedosos, impulsados por el interés reflexivo en función del Derecho y los desarrollos de la práctica jurídica (así, Kelsen ha dicho del deber jurídico muchas más cosas que lo que podían decir los neokantianos, y lo mismo Hart de las reglas jurídicas o Alexy de la teoría del discurso jurídico respecto de Wittgenstein y Habermas respectivamente). La relación entre ambas -filosofía "regional" jurídica y filosofía general- es, pues, compleja. Si se presenta en términos efectivamente polémicos es sobre todo debido al hecho siguiente. Que el afianzamiento del positivismo jurídico como corriente central dominante en el pensamiento jurídico contemporáneo, una vez producido el declive iusnaturalista, ha ido acompañado de una paralela tendencia a la liquidación de la sustantividad de la filosofía (rasgo que comparte con el positivismo general, tanto el decimonónico como el neopositivismo). Sería un caso más de lo que Bueno (1970: 56) llama "muerte positivista" de la filosofía. Así, la filosofía del Derecho se reivindica a si misma como un discurso "de y para juristas" y no "de y para filósofos": como un discurso técnico-práctico propio de la categoría jurídica. Incluso el nomen "filosofía del Derecho" tiende a desaparecer, disolviéndose en el más genérico "Teoría del Derecho", entendida ésta (en la tradición continental) como una disciplina de pretensiones básicamente científicas o doctrinales - una "alta dogmática" construida sobre el molde de la Allgemeine Rechtslehre positivista- o bien (en la tradición anglosajona) una jurisprudence: esto es, en ambos casos un discurso categorial-jurídico, más que "filosófico". ${ }^{4}$ El positivismo jurídico, en célebres palabras de Radbruch, aplica de este modo la eutanasia a la filosofía del Derecho en la medida que ésta quiera reputarse "parte" de un sistema filosófico "apriorístico" al estilo tradicional (tal vez Habermas sea el único exponente actual de esto y probablemente el último). No es la filosofía la que marca "desde arriba" la unidad de ideas de la reflexión sobre el Derecho, sino precisamente la experiencia categorial jurídica, en la medida en que, como dice Bobbio, proporciona los materiales para construir "desde abajo". ${ }^{5}$

11 La preferencia por la filosofía del Derecho de los juristas viene sin duda respaldada por un argumento sumamente potente: la remisión empírica a la categoría jurídica, a los conceptos jurídico-positivos, a la práctica real del Derecho. La iusfilosofía ha de ser una "filosofía del Derecho positivo", construida sobre los problemas que plantean los Estados de Derecho contemporáneos y su compleja tecnificación legal-administrativa o su progresiva constitucionalización, en vez de una reflexión especulativa o improductiva (metafísica o dogmática). ${ }^{6}$ Pero la cuestión decisiva es si esta proximidad con la experiencia categorial jurídica no puede constituir también ella misma un obstáculo -y no necesariamente una ventaja- a la hora de construir un discurso genuinamente filosófico- 
crítico en torno al Derecho. Es decir, si la autocomprension de la filosofía del Derecho como "filosofía de juristas" no puede conducir también a convertirla dogmáticamente en ancilla iurisprudentiae, en una reflexión indistinguible de la especialización gremial jurídica, una simple propedéutica profesional, un patchwork o bricolage filosófico adosado a la propia jurisprudencia ${ }^{7}$, una parte más, en definitiva, de la enciclopedia o la ideología jurídica entendida en un sentido amplio (y no necesariamente negativo). La situación podría compararse, mutatis mutandis, con la que supondría conceder sin más que la filosofía de la religión sólo tiene sentido en cuanto hecha por, y al servicio de, los cultivadores o teólogos de una confesión particular. Este riesgo de "dogmatismo" no sólo ha venido propiciado por la ya mencionada especialización y ubicación institucional de la disciplina, sino también y en buena medida por la metodología del positivismo jurídico, en la que la priorización del punto de vista doctrinal (o "interno") ha significado la insularización del concepto del Derecho y su desconexión de otras categorías, tanto científico-sociales como político-morales. La tesis de la separación entre Derecho y moral, la "pureza" de la teoría del Derecho, el estudio descriptivo o evaluativamente neutro del "Derecho que es" y no del que "debe ser", o la consideración de toda perspectiva "externa" como impertinente para el jurista son manifestaciones de esa metodología que conducen a concluir que la filosofía del Derecho ha de ser ajena a la filosofía moral, a la filosofía política, a la filosofía social, etc. En otras palabras: el discurso iusfilosófico está abocada a ser un discurso relevante sólo para juristas, y no un objeto de interés para "filósofos" o sobre el cual éstos tengan algo interesante que decir.

12 Y este es el punto central que quiero discutir a propósito de la necesidad de repensar y redefinir el status de la filosofía del Derecho. No cualquier discurso sobre el Derecho puede llamarse genuinamente filosófico aunque lleve ese nombre, ni todo discurso filosófico sobre el Derecho puede tildarse, por serlo, de prescindible o dogmático. La contraposición formulada por Bobbio reposa en realidad en una falsa disyuntiva. La desvalorización apriorística de las "filosofías del Derecho de los filósofos" es gratuita: no va dirigida en realidad contra la "filosofía" sino contra alguna filosofía particular cuyos supuestos o tesis se estiman dogmáticos, escolásticos o metafísicos desde alguna otra filosofía particular (en el caso de Bobbio, la iuspositivista). ${ }^{8}$ Del mismo modo, la preferencia por la "filosofía del Derecho de los juristas" puede (y en mi opinión debe) ser asumida sin que ello signifique, sin embargo, abrazar un enfoque insular o puramente endojurídico. La iusfilosofía sólo será verdaderamente filosófica si tiene carácter crítico, y esto exige que sea positiva pero no positivista, vinculada a los conceptos de la experiencia jurídica pero no dogmática, coextensiva con el discurso jurídico-práctico pero no meramente "genitiva": es decir, exige una perspectiva intercategorial, una "totalización" conducente a poner a la categoría jurídica en conexión relevante con otras categorías. ${ }^{9}$ Este es el camino que sigue la filosofía del Derecho postpositivista. Pero esa totalización sólo puede llevarse a cabo en términos de ideas y teorías que necesariamente han de obtenerse de alguna concepción filosófica general, lo que significa que toda iusfilosofía (también la positivista) ${ }^{10}$ es "aplicación" de filosofemas y en consecuencia, por parafrasear a Kant, no está claro si la filosofía de los juristas "lleva por delante la antorcha a su graciosísima dama [la filosofía "general"] o le sigue llevándole la cola"."11

13 De acuerdo con el planteamiento que antes hemos introducido, la filosofía del Derecho al igual que cualquier otra disciplina filosófica- ha de remitirse a ideas filosóficas que establecen el hilo conductor que lleva desde la filosofía regional a la filosofía general o trascendental, ideas que serían esencialmente de dos órdenes: epistemológico y 
ontológico. De modo que el método filosófico es uno y el mismo (sea practicado por juristas o por filósofos) y sólo puede consistir en el doble movimiento que parte de los conceptos categoriales (de los problemas suscitados por éstos, de los que enseguida hablaremos) para analizarlos en términos de ideas o conceptos de segundo nivel y volver a ellos ofreciendo una nueva síntesis o recomposición a la luz de alguna concepción que establezca relaciones relevantes (intercategoriales) entre los mismos. Así, si estos son los dos momentos metodológicos o dialécticos de la racionalidad filosófica -regressus y progresssus- es sencillamente porque los conceptos categoriales pueden ser analizados bien en función de las relaciones existentes entre cada categoría y el tipo de saber o conceptualización que en ella tiene cabida (las clases de saberes, ciencias, conocimientos, etc.), bien en función de las relaciones existentes entre dichos saberes y las realidades categoriales a las que se refieren (qué dominio del mundo acotan, qué entidades atestiguan, qué nexos o leyes determinan, qué objetividad les cabe, etc.). Dicho más sencillamente, aplicado a nuestro caso: la filosofía jurídica elaboraría un mapa de los saberes y de las realidades jurídicas.

\section{El Derecho: ¿concepto o idea?}

14 Hemos dicho que lo que justifica la sustantividad de la perspectiva filosófica es la necesidad surgida en la conceptualización interna a una cierta categoría de una totalización de segundo grado en términos de ideas o esquemas omnicomprensivos que conducen a su desbordamiento -a su crítica- y a su puesta en conexión con otras categorías o conceptos. Pues bien: no se trata meramente de "aplicar" esta comprensión de la racionalidad filosófica a la filosofía del Derecho. Ese sería el error de una concepción dogmática (apriorística o metafísica) de la filosofía. ${ }^{12}$ Se trata más bien de mostrar cómo esa clase de racionalidad está presente -y lo ha estado siempre- en la propia filosofía del Derecho (como en cualquier otra) si es que en ella se está poniendo en práctica el método filosófico. En efecto, es una característica constante del devenir histórico de la filosofía jurídica desde la Grecia antigua la presencia de un mismo método de racionalización de los fenómenos jurídicos según un doble momento de ida y vuelta entre las categorías o conceptos del Derecho y ciertas ideas filosóficas. Aunque esto ha solido restringirse (en la tradición kantiana y hegeliana) a una única idea -la de justicia, contrapuesta al "concepto" del Derecho- esto resulta injustificado: el repertorio de ideas filosóficojurídicas es mucho más amplio y éstas conciernen a todos los conceptos jurídicocategoriales. Cabe sostener que son estos conceptos los que ya están constituidos en su complexión interna por ideas filosóficas. La filosofía del Derecho no "crea" las ideas, sino que las encuentra ya operativas en el Derecho y procede a ordenarlas y sistematizarlas "en segundo grado" más bien que a proyectarlas o "aplicarlas" descendentemente.

Esto permite entender además que la iusfilosofía siempre haya sido una filosofía jurídicamente implantada, esto es, un sistema de ideas de función revolucionaria o emancipatoria, o bien conservadora y legitimadora, respecto de las realidades jurídicas existentes en cada época. Este es un aspecto muy importante de lo que significa que se trata de una filosofía práctica. Tanto el método filosófico como las ideas objetivas con las que trabaja han adquirido en el Derecho significaciones diferentes a lo largo de la evolución de las formas jurídicas. La filosofía del Derecho siempre ha estado correlacionada con las diferentes fases de desarrollo histórico de los propios fenómenos jurídicos. Así pueden ser interpretadas las relaciones históricas entre el Derecho romano 
y el ius commune medieval y la filosofía aristotélico-escolástica (resulta especialmente clamorosa, dicho sea de paso, la omisión que Bobbio hace de la figura de Aristóteles, de quien proviene la idea misma de jurisprudencia, a la que subyace una comprensión epistemológica decisiva de la teoría y la práctica del Derecho común a toda la tradición occidental), o entre la filosofía iusracionalista e ilustrada y el proceso histórico de constitución del Estado y de positivización del Derecho moderno de base nacional. En ambas encontramos filosofías (iusnaturalistas) también de juristas y no sólo de filósofos. Y del mismo modo se entiende que si la filosofía del Derecho surge con ese nombre justamente a partir de la época moderna, y vinculada al conglomerado de doctrinas que llamamos "positivismo jurídico", ello se debe a que es el Derecho positivo mismo el que ha transmutado sustancialmente su morfología y estructura exigiendo una nueva reflexión teórica. La filosofía jurídica podría ser definida así, parafraseando a Hegel, como una época jurídica captada en pensamientos, es decir, en ideas, comenzando por la propia concepción general del Derecho, que no sería entonces un concepto sino más bien una idea

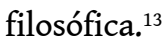

16 Si asumimos una concepción funcional-histórica de la filosofía jurídica como la anterior, podemos ver que las ordenaciones de ideas que le son propias no han de ser buscadas tanto en ella (ni en la filosofía "de filósofos") cuanto en la propia realidad categorial que constituye su objeto de análisis, esto es, el propio Derecho. Esto es una consecuencia de entender (frente a cualquier metafísica) que las ideas de que hablamos están dadas en el proceso histórico y social, no son ideas pertenecientes a un topos uranos ideal (pero tampoco meras ideologías contingentemente ligadas a grupos o clases). Son los cambios en las realidades jurídicas los que llevan a ideas filosóficas que, a su vez, permiten reconstruir y entender mejor esos cambios e influir sobre ellos por medio de nuevas ideas. Por eso, antes de responder a la pregunta de cómo se aplica la filosofía al Derecho o para qué hay que plantearse por qué es necesaria tal aplicación: por qué el Derecho tiene la necesidad de incorporar una reflexión filosófica, sea ésta hecha por juristas o por filósofos.

Para desarrollar la tesis sugerida en la pregunta anterior necesitamos considerar dos cuestiones. La primera es qué significa decir que el Derecho es una "categoría". La segunda es identificar qué clase de "totalización crítica" es relevante a propósito de ella como para ser susceptible de conducir a una verdadera reflexión filosófica.

Plantear si el Derecho es una categoría es tanto como indagar qué tipo de conceptualización exhiben los fenómenos jurídicos (epistemología) y qué clase de realidad poseen (ontología). Sería difícil encontrar una visión del Derecho que negase que la categoricidad del Derecho es esencialmente práctica, en la medida en que es una técnica social institucionalizada. Su "positividad" va ligada a este hecho (y no es casual que sea la categoría práctica del Derecho el primer lugar en el que esta misma idea de "positividad" surge, antes incluso del "positivismo"). Hasta el iusnaturalismo incluye, en cuanto teoría dualista del Derecho, la "tesis social" que el iuspositivismo convirtió en redundante: sólo el producido por las prácticas humanas es "Derecho", sin más calificación. La dimensión "técnica" del Derecho es inseparable de su carácter "artificial", como actividad o producto de agentes que no por casualidad se llaman "operadores" jurídicos. La categoricidad del Derecho está vinculada también a su normatividad. Las instituciones jurídicas (legislativas, judiciales, ejecutivas) consisten en prácticas concatenadas encaminadas a la producción y aplicación continuada de normas. Son además prácticas de segundo orden, por cuanto que las operaciones institucionales 
jurídicas tienen un anclaje social: presuponen prácticas y normas dadas en primer grado y su función es establecer una determinada ordenación respecto de ellas interfiriendo mediante operaciones y decisiones en su curso. La estructura institucional del Derecho está así situada en un lugar intermedio entre las instituciones morales y las instituciones políticas. Las normas jurídicas, resultantes de esta estructura institucional práctica, cuentan como las reglas sociales últimas (es decir, finales o definitivas: no, por supuesto, moralmente infalibles).

Si se aceptan estas premisas generalísimas cabe obtener ya de ellas la clave de la noción de "totalización" a la que nos venimos refiriendo. Atienza (1989: 371-2) apunta a la idea fundamental:

La función de la filosofía del Derecho en el conjunto de la cultura jurídica es semejante a la que desarrolla el Derecho en el conjunto de la sociedad. Del Derecho se dice que es un sistema de control social porque supervisa y, en alguna medida, dirige el funcionamiento de las instituciones sociales; lo jurídico no es atributo exclusivo de ciertos sectores o instituciones sociales, sino que -empleando de nuevo la metáfora de C. Nino- es algo que, como el aire en el mundo físico, está por todas partes. La filosofía del Derecho no tiene tampoco un terreno acotado en exclusividad en el conjunto de los saberes jurídicos y sociales, sino que su campo es más bien el de las relaciones entre estos diversos sectores de la cultura; su lugar está, precisamente, en las fricciones y en los vacíos que se producen en el funcionamiento de los mismos.

Si la filosofía jurídica es una reflexión de carácter totalizador, es porque el propio Derecho constituye ya per se una institución totalizadora, una pars totalis del todo social, que precisamente por eso exige el recurso a ideas filosóficas.

21 Kant dijo célebremente que ante la pregunta por el concepto del Derecho (quid ius) los juristas sólo pueden responder tautológicamente remitiéndose a lo que es "de Derecho" ( quid iuris), es decir, a "lo que dicen o han dicho las leyes en un determinado lugar y en un tiempo determinado". Esta remisión "puramente empírica" a la categoricidad o positividad jurídica es, dice Kant, insuficiente: "Una teoría jurídica únicamente empírica es - como la cabeza de madera en la fábula de Fedro- una cabeza que puede ser hermosa, pero que lamentablemente carece de seso". Se refiere con ello a la necesidad de adoptar una perspectiva filosófica: es preciso buscar una vía "racional" que funde el concepto del Derecho "Abandonando esos principios empíricos para buscar sus fuentes en la pura razón". ${ }^{14}$ Pues bien, lo que quiero explorar es en cierto modo el camino inverso al señalado por Kant. Las ideas de la filosofía jurídica no deben ser buscadas en ninguna razón "pura" apriorística (en el imperativo categórico), sino en las propias prácticas categoriales jurídicas. Cuando éstas establecen lo que es "de Derecho" (lo que está jurídicamente ordenado o debido) ya están presuponiendo necesariamente alguna concepción sobre qué es el Derecho (quid ius), y son precisamente estas concepciones las que involucran aquellas ideas filosóficas que forman el campo de reflexión de la filosofía jurídica. Se trata entonces de mostrar que la practicidad de la categoría jurídica no es en realidad meramente empírica y no implica la simple alusión denotativa a las "prácticas jurídicas" o al Derecho como "práctica social" en el sentido de un "hecho" o una "convención" (tal como también es frecuente entender entre los positivistas), sino que incluye elementos de universalidad y objetividad que la llevan a trascender su dimensión fáctica (sin por ello incurrir en metafísica). Tales elementos universales y objetivos -que, como veremos, no son otros que los valores- son componentes necesarios de la propia 
racionalidad jurídica, del propio discurso del Derecho, y hacen que sus conceptos desborden característicamente el marco categorial en que surgen.

\section{Ubi ius, ibi philosophia}

Vamos con la noción de "totalización". Lo que hace que las conceptualizaciones de la categoría jurídica posean alcance filosófico no es simplemente que contengan "totalizaciones". Estas son propias de cualquier categoría, del mismo modo que toda categoría científica o técnica supone el ejercicio de la crítica a un cierto nivel. Como antes dijimos, la totalización distintivamente filosófica aparece en un contexto pluricategorial, por tanto trascendental. Y así sucede con los conceptos jurídicos en la medida en que, a tenor de su configuración práctica y normativa, suponen la conexión y síntesis entre categorías distintas: morales, políticas, sociales, económicas, etc. El tipo de totalización normativa que es característico de la categoría jurídica la aproxima enormemente a la filosofía. Lo cual no quiere decir que el Derecho tenga por objeto "resolver problemas filosóficos", pero sí que los problemas prácticos que el Derecho encara no pueden ser resueltos sin hacer uso de ideas y concepciones de carácter filosófico. Por lo demás, no hay que olvidar que los orígenes mismos de la filosofía en Grecia están muy vinculados a la discusión de problemas de todo orden -lógicos, morales, políticos, etc.- planteados precisamente desde las categorías jurídicas. ${ }^{15}$

Pero, además de esta dimensión pluricategorial, hay un segundo rasgo de la categoría jurídica que hace que sus conceptos, sin dejar de serlo, tengan que realizar "totalizaciones" filosóficas. Debido a su institucionalización, el Derecho es una práctica colectiva, un agregado de subinstituciones de gran complejidad y dotadas de alta especialización interna que operan en función de operaciones de sujetos diversos, en situaciones distintas y a lo largo de extensos segmentos temporales. Esta diversidad múltiple de partes funcionales hace que la unidad y coherencia de fines dentro de la práctica jurídica sólo resulte posible si ésta incorpora dispositivos específicos de racionalización reflexiva para llevar a cabo sus funciones de producción y aplicación de normas. El Derecho constituye así en buena medida un corpus de "doctrina", es decir, práctica normativa más teoría internamente acoplada. Su faceta de técnica de control social es inseparable de una dimensión de técnica reflexiva, "ideológica", doctrinal, que implica un elevado grado de abstracción en el planeamiento de la acción social. El desempeño de la práctica jurídica depende de un complejo instrumentarium conceptual y teórico en el que cabe diferenciar al menos dos géneros. ${ }^{16}$ Por un lado, están aquellas doctrinas o teorías de carácter formal que explicitarían los recursos y procedimientos de tipo técnico y metodológico vinculados a la práctica jurídica como práctica "formalista", esto es, centrada en las normas jurídicas en su papel de "formas" o estructuras mediante las que tiene lugar su intervención sobre la acción social (fundamentalmente reglas y principios). Estas doctrinas suministran fundamentalmente una identificación, clasificación y jerarquización de las normas jurídicas (una teoría de las "fuentes"), así como las reglas y procedimientos para su implementación práctica (una teoría del "método" o la interpretación). Y, por otro lado, tenemos aquellas teorías de carácter material que suministran concepciones globales relativas a los contenidos normativos sustantivos, los fines y valores a cuya consecución el sistema jurídico se orienta mediante las técnicas y métodos anteriores (p. ej., una concepción de los derechos fundamentales). Ambas clases de teorías o doctrinas, siempre mutuamente entretejidas, componen ya una 
verdadera ontología y epistemología jurídicas, es decir, una "filosofía del Derecho" en ejercicio. Forman lo que se ha podido llamar "paradigma jurídico", "razón jurídica", "ideología jurídica", "conciencia jurídica común", etc., pero que puede verse también como una verdadera "filosofía mundana" o "profesional" del Derecho o "filosofía espontánea de los juristas" que envuelve una autoconcepción ad intra del Derecho y una "concepción jurídica del mundo", es decir, una interpretación ad extra de la realidad (social, política, económica, natural) hecha desde la racionalidad jurídica como racionalidad de segundo grado.

Un tercer aspecto fundamental de estas totalizaciones de la racionalidad jurídica que aproxima de forma decisiva su formato al de las totalizaciones filosóficas tiene que ver precisamente con esa dimensión de normatividad de segundo grado. Me refiero al hecho de que ésta tiene un carácter constitutivamente dialéctico: es decir, está vinculada de manera estructural al conflicto, al desacuerdo, a la desviación, a la incompatibilidad, a la contradicción, a la inconmensurabilidad, a la controversia. Por tanto, su racionalidad consiste esencialmente en el despliegue de estrategias orientadas a la gestión y desbloqueo discursivo y argumentativo de tales conflictos e inconmensurabilidades. Este aspecto tiene que ver obviamente con el hecho de que el Derecho es la institución social centralmente encargada en términos de "ultimidad" (ultima ratio) y monopolio coactivo de resolver los conflictos y lograr la cooperación y coordinación a escala colectiva. Pero esto determina justamente que sus normas y decisiones sean el resultado de una "sintaxis" o composición de partes o elementos esencialmente plurales o heterogéneos que se presentan en conflicto y desajuste permanente. No hace falta insistir en que este es el caso tanto en la práctica de producción normativa (legislativa, constitucional) como en la de aplicación (judicial, administrativa). La construcción lógica de clases o tipos de acción y la individualización o concreción de situaciones prácticas singulares a partir de ellos son operaciones de totalización, y lo mismo sucede con los razonamientos de tipo finalista (composición de intereses y propósitos) y de ponderación (composición de valores) de los que las normas y decisiones jurídicas son resultado. Los problemas prácticos que acomete el Derecho en ambos casos son por ello muy semejantes a problemas filosóficos. Como éstos, suponen conflictos que por su naturaleza de algún modo vienen a comprometer o poner en cuestión a la categoría entera y conducen "desde dentro" a su desbordamiento. La principal manifestación de esto va considerablemente más allá del hecho de que cada decisión legislativa o judicial comporte un regressus holístico al "sistema jurídico" en su conjunto como un todo (la "integridad" dworkiniana, p. ej.). Se trata además de que esta sistematización no puede ser meramente lógica o formal. El sistema jurídico no es un "sistema lógico" sino un "sistema práctico", doctrinal, prudencial o justificativo (aunque, naturalmente, sus justificaciones no pueden excluir la lógica). Y ello implica que no es una categoría "cerrada" por aplicación de su propia metodología conceptual y teórica interna (tal como sucedería si fuera una categoría científica), sino que se trata de una metodología que presupone el carácter esencialmente "abierto" de la práctica jurídica. Dicho de otro modo, su "cierre" sólo puede darse incorporando argumentativamente elementos provenientes de otras categorías. Tales elementos, dado que el Derecho es un sistema de segundo grado, no pueden ser sino los fines y valores envolventes que mediante el aparato jurídico se pretende materializar en las prácticas sociales de primer grado, fines y valores que él mismo no crea sino reconoce y conforma prácticamente. Se trata, pues, de los contenidos incorporados en las que antes hemos denominado "teorías materiales", que son concepciones sustantivas de carácter 
necesariamente político-moral (y por ello "filosóficas" en el sentido apuntado) de las que se sirve y en las que se funda necesariamente la conducción de la práctica jurídica.

\section{La filosofía del Derecho como filosofía práctica}

Si la racionalidad jurídica se presenta del modo apuntado a concepciones "filosóficas" que forman parte interna necesaria del Derecho mismo en cuanto sistema doctrinal, entonces éste ya cuenta con una filosofía propia o "genitiva" del Derecho. Las concepciones teóricas que habitualmente se consideran como pertenecientes a la filosofía académica del Derecho (iuspositivismo, formalismo, iusnaturalismo, constitucionalismo, realismo, etc.) son también filosofías que la "filosofía profesional" de los juristas hace suyas, de modo especialmente visible en los estratos de mayor abstracción doctrinal de la práctica jurídica, que son también los de mayor alcance (como los tribunales constitucionales). Aquí se halla, entonces, el punto de contacto de la filosofía jurídica en cuanto disciplina con el Derecho: las concepciones filosóficas del Derecho son parte de su práctica y las teorías conformadoras de la práctica jurídica presentan una zona de superposición con la filosofía del Derecho.

La filosofía jurídica en sentido estricto o académica podría definirse entonces como aquella reflexión formalmente filosófica que se orienta a la sistematización de las ideas que ya cuentan con un nivel de desarrollo reflexivo categorial dentro del Derecho. Es aquí donde, como hemos dicho, hay que corregir considerablemente la valoración general que hace Bobbio de la contraposición entre la filosofía del Derecho de juristas y filósofos. Ella distorsiona el hecho de que toda filosofía del Derecho, sea de filósofos o de juristas, ha consistido siempre (y no se entiende cómo podría ser de otra forma) en la aplicación de esquemas filosóficos más o menos sistemáticos al Derecho. Por un lado, Bobbio no presta la atención suficiente a la circunstancia de que el Derecho es una institución históricocultural que plantea genuinos problemas filosóficos para cualquier filosofía, y en tal medida siempre ha sido un objeto presente en las ideas acuñadas por las grandes filosofías generales de la tradición occidental, dentro de lo que desde Aristóteles conocemos como "filosofía práctica" (la politiké) que comprende la filosofía moral o ética, la filosofía política o la filosofía social. Baste mencionar la idea de "ley" (lex), cuyo uso práctico es un resultado de la síntesis de diferentes acepciones categoriales: morales, científicas, jurídicas. Las "cuestiones persistentes" (Hart 1994: Cap. I) suscitadas por el Derecho plantean problemas filosóficos generales: como su relación con las ideas de poder, normatividad, sociedad, justicia, moral o verdad científica. Por otro lado, la preferencia general por la filosofía del Derecho de los juristas resulta injustificada. Que sean los juristas quienes por razón de su formación se hallan en mejores condiciones para emprender una reflexión filosófica que parta directamente de las categorías jurídicas (algo que les viene impuesto por su propia metodología positiva) explica que la iusfilosofía académica haya sido cultivada fundamentalmente por "juristas-filósofos". Pero no garantiza ninguna inmunidad absoluta contra la metafísica o el dogmatismo. En todas las épocas históricas los juristas han procedido a la apropiación de filosofías generales para la elaboración de sus doctrinas (pues es la categoría jurídica misma la que siempre ha necesitado de una $u$ otra envoltura filosófica para construir su metateoría interna). Puede decirse que no ha habido doctrina filosófica que no haya recibido una incorporación o adaptación al campo jurídico (el tomismo, el kantismo, marxismo, el hegelianismo, el pragmatismo, la fenomenología, el neoempirismo, la filosofía lingüístico- 
analítica, la hermenéutica, la teoría del discurso, el posmodernismo y cualesquiera otros "ismos" filosóficos). Las muestras de filosofía "aplicada" que Bobbio censura son obra también de juristas, y no sólo de filósofos que descienden "especulativamente" al campo del Derecho. Lo que demuestra que no es esta "aplicación" de sistemas filosóficos por sí misma la que merece apriorísticamente el calificativo de metafísica o dogmática, sino las tesis, conceptos, métodos concretamente aplicados. ${ }^{17}$

Más bien lo que la historia de la iusfilosofía nos muestra es un continuum de ideas que tienen al Derecho como punto de convergencia y que son moduladas de distinta forma (pero no de forma mutuamente excluyente) por sistemas filosóficos generales históricamente dados y por la filosofía académica del Derecho como disciplina jurídicamente implantada. Las concepciones filosóficas de los juristas, que son como hemos visto totalizaciones internas a la propia categoría jurídica, demandadas por el tipo de problemas que aborda la práctica del Derecho, constituyen la zona de intersección entre ambas. Tales concepciones constituyen sin duda el mejor acceso filosófico al Derecho disponible por cuanto suministran el repertorio básico de las ideas filosóficojurídicas, y en este sentido han de poder ser incorporadas por cualquier filosofía del Derecho que pretenda no ser metafísica o desentendida de la experiencia jurídica. Pero también tienen que ser objeto de crítica y reelaboración en términos filosóficos generales o trascendentales, sin que puedan pensarse propias de un discurso puramente endojurídico o intracategorial. Y esa crítica implica que la filosofía jurídica ha de entroncar necesariamente con la filosofía moral y la filosofía política, esto es, ha de construirse dentro del marco de alguna concepción de la filosofía práctica general entendida en perspectiva trascendental. En lo que sigue veremos, muy esquemáticamente, algunos de los principales argumentos con los que cabe sustentar esta afirmación.

El argumento central nos reconduce nuevamente a considerar el tipo de totalizaciones que caracteriza a la categoría jurídica y se manifiesta en sus concepciones internas. Estas son totalizaciones de naturaleza esencialmente justificativa. Dado que el Derecho es una categoría práctica y normativa, los conceptos jurídicos son conceptos doctrinales. Su función principal como conceptos prácticos es no sólo guiar la acción (aspecto "técnico") sino hacerlo justificadamente. Los conceptos jurídicos están ligados a la práctica de argumentar y dar razones en relación con las decisiones jurídicas, de justificar la acción ( ex post y ex ante). Esto supone que lo que hasta ahora hemos llamado las ideas que conforman la práctica jurídica son en realidad "ideales" ${ }^{18}$ o, en términos de Kant, "ideas regulativas". ${ }^{19}$ En otras palabras: son valores.

Los valores constituyen los verdaderos componentes trascendentales de la práctica jurídica. Así cabe afirmarlo tras examinar cualquier inventario de los conceptos jurídicos fundamentales: conceptos tales como "persona", "acción", "norma", "ilícito", "sanción", "responsabilidad", "derecho", "deber", etc., que representan una categorización de las nociones básicas de la filosofía práctica (la philosophia practica universalis de la tradición). Es el manejo esencialmente justificatorio de estos conceptos en la práctica jurídica lo que hace necesario acudir a concepciones (que antes llamábamos "materiales") capaces de suministrar versiones o interpretaciones de los mismos en términos de conglomerados de juicios de valor de carácter fundamentador. Tales valoraciones están a la base del método jurídico, que en realidad parte de presuponer la ineliminable "apertura" o "indeterminación" del sistema jurídico y la necesidad de "cerrarlo" o determinar su contenido recurriendo a justificaciones prácticas de ese tipo. ${ }^{20}$ Los conceptos jurídicos son 
siempre elisiones de juicios de valor. ${ }^{21}$ Todo el complejo técnico-práctico del Derecho formado centralmente por las reglas como unidades instrumentales básicas del trabajo del jurista- es el resultado de ponderaciones o balances entre valores y por eso la aplicación práctica de los conceptos en ellas plasmados va inseparablemente unida a los juicios de valor subyacentes y a la necesidad de fundamentarlos en términos de validez objetiva. Los desacuerdos que están en el origen de las reglas -en tanto "expresiones de compromisos, o juicios acerca del resultado de conflictos" 22 - se reproducen permanentemente en su proceso de aplicación, de forma que determinar los "fundamentos de Derecho" de cada nuevo caso requiere la explicitación de los valores en juego y en última instancia de su fundamento ético-político. De ahí que sea preciso formarse alguna concepción de los principios (que son la expresión normativa de valores) y la reconstrucción integral del Derecho involucrada en la resolución de cada caso, por más que ello sólo parezca especialmente visible en los casos difíciles o en los problemas jurídicos que suscitan desacuerdos morales típicos (aborto, eutanasia, matrimonio homosexual, gestación subrogada, etc.). Todas las cuestiones jurídicas, incluyendo los casos fáciles, son cuestiones de principio en este sentido, es decir, cuestiones de valor. ${ }^{23}$

Es necesario entonces "recurrir a una filosofía moral y política que permita articular, establecer, algún orden entre los diversos tipos de razones justificativas que concurren en el Derecho". ${ }^{4}$ Esta filosofía comprende combinaciones de ideas acerca del bien común, del interés general, de los derechos humanos, de fines o metas colectivas, etc., y se resuelve en última instancia en algún tipo de fundamentación de los valores ético-morales de carácter final (libertad, igualdad, dignidad) y de los valores políticos en cuya virtud se justifican el poder y la autoridad (una concepción de la democracia, del Estado, etc.). Es decir, se resuelve en lo que desde Aristóteles llamamos la justicia como esquema básico articulador de ideas acerca de lo bueno y de lo correcto en la distribución y la reparación tanto en los asuntos públicos como privados que integran el territorium de la praxis humana. ${ }^{25}$ De este modo, la dimensión justificativa del Derecho lo conecta internamente, desde su propia práctica, con concepciones de calado filosófico-moral y filosófico-político. Desemboca en sistemas generales u omnicomprensivos de filosofía práctica (de orientación liberal, utilitarista, comunitarista, deontológica, social, etc.) desde los cuales, a su vez, tiene lugar la orientación y crítica normativa de aquellas concepciones jurídicas. Estas funciones normativas corresponden esencialmente a la filosofía del Derecho académica, punto natural de intermediación entre el Derecho y la filosofía práctica, que entonces se revela ella misma igualmente como una empresa práctica. La filosofía del Derecho es la filosofía práctica que sigue al Derecho como su sombra. Los valores en él presentes como fundamentos trascendentales y simultáneamente como ideas de la filosofía práctica forman el puente de ida y vuelta entre ambas.

31 Cabría incluso sostener que la filosofía jurídica es aquella región (o "parte") de la filosofía práctica que goza de un cierto "primado" sobre las demás. Pues el Derecho no es sólo un lugar de realización y plasmación de los valores político-morales (una plasmación decisivamente eficaz debido a que la institucionalización jurídica gestiona la coacción pública) y donde por ello estos valores adquieren una justificación de carácter definitivo, sino también el lugar en el que por ello vienen a confluir también, desde su propia perspectiva trascendental, la filosofía moral y la filosofía política en iguales términos. En efecto, y de otro modo no se entendería la crítica político-moral del Derecho establecido, las instituciones jurídico-prácticas aparecen para aquéllas como un punto de llegada necesario, como una malla o arquitectónica histórico-cultural que es condición de 
posibilidad de la propia moralidad y de la sociedad política, al margen de la cual éstas sencillamente no se darían o se desintegrarían. El Derecho representa no sólo la autodescripción ideológica de una sociedad, sino también su propia autojustificación política y moral, donde todos los valores prácticos se "personifican" en términos de ultimidad: es decir, se imputan a la comunidad como un todo (una forma evidente de “totalización"). El Derecho se vincula así con la idea misma de "razón pública". ${ }^{26}$ Es este un hilo rojo que recorre toda la historia de la filosofía práctica desde Aristóteles a Kant, por citar sus dos hitos fundamentales.

Se comprende entonces el sentido profundo en que la perspectiva genuinamente filosófica en torno al Derecho puede entenderse unida a la noción de "totalización crítica". Esta tiene que ver esencialmente con la función justificativa del Derecho, que opera sobre la base de valores prácticos. No sólo se trata de la prevalencia de esta dimensión justificativa del Derecho sobre su dimensión técnica o directiva, debido a que los problemas sobre los que versa envuelven conflictos y desacuerdos que en última instancia son de índole axiológica e intentan ser resueltos en iguales términos; no sólo se trata de que la práctica del Derecho deba regirse por un método de construcción y reconstrucción permanente de la coherencia o "integridad" de los materiales jurídicos y que la práctica de justificar (el método jurídico) aparezca como una operación interpretativa compleja que supone efectivamente "totalizar" cada caso en virtud de múltiples criterios (relevancia, calificación, aplicabilidad, verdad, adecuación, ponderación, etc.) para de este modo integrarlo en el sistema jurídico como un todo (as a whole, dice Dworkin 1986: 400-1, 411), recapitulando en algún sentido en cada decisión el conjunto de los instrumentos técnicos del Derecho positivo. Se trata además, y sobre todo, de que ello exige necesariamente traspasar la categoría jurídica para mostrar al Derecho como una técnica precisamente político-moral. La técnica jurídica en conjunto y cada una de las decisiones en que se decanta a lo largo de su curso continuado (en ese segundo nivel reflexivo sobre las prácticas sociales en que se construye institucionalmente) tienen que aparecer como una práctica justificada que sirve a los valores de justicia y moralidad. La integridad "inclusiva" reenvía a su vez una integridad "pura", ${ }^{27}$ aspiracional, en cuyos términos resulta justificado el Derecho como institución que realiza valores pero también, y sobre todo, resulta criticado en la medida en que no lo haga.

33 Y esta es la razón por la que el problema del Derecho injusto, de la validez de las normas y decisiones jurídicas, es un problema trascendental que pone "en tela de juicio" a toda la categoría jurídica ("no hay derecho") y vuelve "defectuosas" o lastradas de un déficit (axiológico y por ello jurídico) a algunas de sus decisiones particulares, cuando se presentan como pese a todo irremediablemente injustas. Así queda reconocido en tópicos como Antígona, los magna latrocinia agustinianos o la "cláusula Radbruch" que hacen aflorar la pretensión de corrección del Derecho (Alexy) o ponen de manifiesto que es un sistema práctico que reclama autoridad moral (Raz). Es el carácter esencialmente totalizador y conflictivo de los valores prácticos involucrados en la institución jurídica los valores de la justicia o, mejor dicho, las demandas de la injusticia ${ }^{28}$ - lo que hace que el concepto de Derecho reenvíe a la filosofía y que ésta sea esencialmente una filosofía práctica.

34 La racionalidad justificativa jurídica se asienta así sobre una constante tarea práctica de conexión o conjugación partes extra partes que lejos de responder a una "armonía preestablecida", es esencialmente "abierta", asimétrica y polémica (lo que resulta tanto de que las prácticas jurídicas deban ajustar constantemente con el fluir de las prácticas 
sociales de primer grado, como de su propia lógica institucional autónoma como maquinaria "técnica"). Partes del Derecho interfieren con partes de la moral y con partes de la política de diversos modos, a lo largo de niveles distintos, y no siempre (por no decir casi nunca) armónicamente entre sí. ${ }^{29}$ Pero las tensiones entre ellas deben sin embargo recomponerse en clave justificativa unitaria, en forma de totalizaciones finales de los valores implicados. Se trata de las tensiones existentes entre la eficacia del poder o autoridad y la validez sustantiva, entre justicia y seguridad jurídica, entre dura lex, sed lex y summum ius, summa iniuria, entre los límites políticos del Derecho y las pretensiones de los derechos universales, entre la idiosincrasia socio-cultural de cada comunidad jurídica y las exigencias de la moral crítica, entre los valores institucionales de la técnica jurídica (ligada a la continuidad de operaciones pasadas, a la igualdad formal, a unas pautas hermenéuticas específicas vinculadas a su dimensión lingüística...) y los valores sustantivos de justicia, entre los principios mismos de justicia que el Derecho incorpora y su necesaria estabilización mediante reglas, entre la racionalidad que rige el sistema y la presencia inevitable de decisiones irracionales, etcétera. Sólo mediante diferentes concepciones del valor internas a la práctica jurídica (como parte de las distintas concepciones del Derecho) puede llegarse a alguna clase de articulación unitaria de este escenario esencialmente conflictivo que sea capaz de establecer "consensos entrecruzados", "equilibrios reflexivos", criterios de "razonabilidad", ponderación o "proporcionalidad", "acuerdos incompletamente teorizados", etc. Ello es el resultado de interpretaciones que suponen un cuestionamiento de la categoría jurídica como un todo a la luz de valores y al mismo tiempo conduce a restablecer la unidad de la razón práctica en torno a los mismos. Tal necesidad de interpretar valorativamente la categoría jurídica en términos de totalidad desde el conjunto del espacio práctico determina que el concepto doctrinal del Derecho posea prioridad epistemológica sobre todos los demás (sociológicos, económicos, lógicos, etc.). ${ }^{30}$ También que sea un "concepto esencialmente contestado" o un "concepto interpretativo": es decir, un concepto filosófico, una idea. Y, en definitiva, que deba darse una continuidad sustancial e ininterrumpida entre ambos.

Y también puede entenderse mejor, por último, el sentido de la tesis de que la filosofía jurídica no constituya meramente una filosofía adjetiva o genitiva. Esta sería precisamente aquella en la que los valores que conciernen al Derecho no figuran como trascendentales. Es decir, donde son entendidos bien como valores puramente externos a la racionalidad jurídica (propios de la filosofía moral o política pero no de la filosofía jurídica) o bien como valores puramente internos a la institución jurídica (no conexos con la moral y la política, esto es, no trascendentales). Una clara formulación de ambas ideas la encontramos en Kelsen, cuando afirma que "dado que la justicia es un postulado de la moral, la Filosofía del Derecho constituye una rama de la filosofía moral o ética"; es decir, la filosofía del Derecho en la medida en que se ocupe de los valores deja de referirse al Derecho: de éste sólo se ocupa en rigor no una "filosofía jurídica", sino una "Teoría general del Derecho" de carácter científico cuya función es descriptiva y no normativa: que "tiene como objeto al Derecho tal como de hecho es, es decir, el Derecho positivo, tanto nacional como internacional" y cuyo objetivo consiste en "analizar la estructura del Derecho positivo y en fijar las nociones fundamentales en el conocimiento de ese Derecho". ${ }^{31}$ Esta idea es la que ha prevalecido en la corriente central del positivismo jurídico contemporáneo, en su tenaz intento de separar el ser del Derecho de su deber ser, de aislar las "cuestiones conceptuales" de las "cuestiones normativas". Hart la considera incluso su tesis más nuclear. ${ }^{32} \mathrm{El}$ iuspositivismo es, en efecto, la encarnación más emblemática (aunque tal vez no la única) del punto de vista que supone la segregación de 
los valores sustantivos del Derecho del campo de la filosofía jurídica o su reducción a valores estrictamente internos (técnicos o categoriales: fundamentalmente los valores formales o institucionales del Derecho). Cosas ambas que suponen la liquidación de la filosofía del Derecho, en el primer caso porque no sería propiamente una filosofía jurídica, sino una filosofía moral o política, y en el segundo porque su estudio ya no sería propiamente filosófico sino científico (o técnico), pues la reconstrucción de los conceptos jurídicos podría llevarse a cabo, se afirma, al margen de todo juicio de valor de carácter justificativo. ${ }^{33}$

36 Así, nos dice por ejemplo Ferrajoli, referirse a los valores de la justicia implicaría adoptar un punto de vista externo sobre el Derecho: "el punto de vista de la política, que contempla al Derecho positivo vigente y a las instituciones jurídicas de los diferentes ordenamientos como un producto histórico, político y social, que debe ser construido (o demolido), defendido (o criticado) y conservado (o transformado)", un punto de vista que parte de los valores que diseñan y proyectan el deber ser externo o ético-político del Derecho y que permiten formular respecto de éste juicios sobre su mayor o menor grado de justicia (o de injusticia)". Pero "en otro nivel completamente diferente se sitúa la Teoría del Derecho, que es una teoría formal que se limita al análisis de los conceptos técnico-jurídicos y de sus relaciones sintácticas". Esta teoría es "formal" o estructural, de naturaleza esencialmente lógica o científica, una "metateoría" de los conceptos jurídicos que toma a éstos como "ideológicamente neutrales, es decir, independientes de cualquier sistema de valores internos o externos a los ordenamientos investigados". ${ }^{34}$ La Teoría del Derecho pretende, pues, ser la verdadera disciplina sustitutiva, por vía científica categorial- de la filosofía jurídica. 0 , expresado de otra manera pero con el mismo resultado, la filosofía jurídica es -para Guastini- "filosofía de la jurisprudencia", un análisis del discurso de los juristas de carácter "meramente conceptual" cuya función es modelar los conceptos aptos para describir el Derecho, pero no modelar al propio Derecho, "no incidir de ningún modo sobre la identificación del contenido del Derecho mismo, el cual por hipótesis, cuando se debate de filosofía del Derecho, no está en discusión". ${ }^{35}$ Los valores del Derecho resultan, en suma, sólo identificados como hechos sociales atribuidos y no como valores cuyo reconocimiento suponga un compromiso práctico conducente a convertir cualquier discurso relativo a ellos en discurso normativo y, en particular, al discurso de la filosofía jurídica. ${ }^{36}$ Tal compromiso no involucraría más que valores epistémicos, pero no propiamente sustantivos: se trataría simplemente de describir valoraciones, aquellas que están presentes en la justificación del Derecho, sin que ello exija una teoría justificativa o normativa a su vez. Los valores que hacen que el Derecho sea una institución normativa y justificativa son solamente valores transferidos, teóricos o epistémicos, no necesariamente valores prácticos (compartidos o rechazados). ${ }^{37}$ La filosofía jurídica no es normativa o práctica en un sentido justificativo fuerte, sino una empresa teórica ("conceptual" o exenta de normatividad).

Pues bien, resulta evidente que la crítica filosófica del punto de vista anterior sólo puede llevarse a cabo en términos epistemológicos y ontológicos, tal como antes decíamos. Por un lado, esa crítica ha de mostrar que la pretensión filosófica de reconstruir conceptualmente la validez jurídica como despojada del valor o value-free se funda en una comprensión errónea de la epistemología del discurso jurídico-normativo y de sus condiciones de cientificidad. La categoría jurídica no es científica precisamente porque los conceptos jurídicos - los conceptos de la dogmática jurídica, de la "Teoría general del Derecho" y de su sucesora la Teoría del Derecho entendida como ciencia- son 
estructuralmente valorativos y están fundados en tomas de posición inexcusablemente morales y políticas. No hay, pues, una ciencia jurídica que se muestre capaz de distanciarse o liberarse epistémicamente ("teóricamente") del compromiso práctico con los valores sustantivos del Derecho. Cualquier discurso metalingüístico que maneje los conceptos jurídicos en los que tales valores se plasman cumple funciones internas al lenguaje objeto de la práctica jurídica: funciones de fundamentación o crítica que hacen de él más un metalenguaje del Derecho (esto es, generado desde el punto de vista interno o del participante para intentar "cerrar" conceptualmente la categoría jurídica) que sobre el Derecho. Pero ni los conceptos técnicos ni los científicos (doctrinales) del Derecho consiguen que la categoría jurídica sea "cerrada" o autorreferencial: por el contrario, su implantación práctica hace que la normatividad jurídica sea de estructura permanentemente abierta $^{38}$ y reenvíe de forma necesaria a otras categorías o nociones morales y políticas. Que la categoría jurídica no sea estrictamente científica o técnica, sino más bien una práctica doctrinal, no supone menoscabo alguno de su racionalidad: sólo significa que es una racionalidad de tipo práctico, político-moral, que sólo puede articular y "cerrar" en forma unitaria sus conceptos haciendo uso de ideas de naturaleza filosófica, ideas que versan sobre los valores político-morales básicos.

Así, la "pragmática" de la Teoría del Derecho, nos dice Ferrajoli, se refiere a los mismos principios del Derecho (o sea, sus valores) vistos como la "lógica" rectora del mismo, sólo que en tanto principios iuris tantum y no iuris et de iure, dado que la estructura nomodinámica del Derecho, sujeta a divergencias y contingencias históricas, no siempre haría posible que resulten satisfechos. ${ }^{39}$ Pero esto no es sino una manera distinta de decir que el Derecho constituye una empresa práctica cuya función es totalizar esos valores, que se mantienen conflictivamente dentro y fuera de la categoría jurídica, a los cuales por ello mismo no cabe entender como valores únicamente epistémicos (lógicos), puramente descriptivos o analíticos, es decir, teóricos. Envuelven el compromiso práctico con concepciones sustantivas de la justicia a partir de combinaciones y especificaciones de esos principios. Sólo así permiten la crítica ético-política del Derecho establecido: una crítica que entonces es tanto interna como externa, es decir, trascendental o filosófica. La pragmática de la Teoría del Derecho es una dimensión más de la práctica jurídica: ésta no es una disciplina teórica, bajo ninguna acepción epistemológica rigurosa de este término, ${ }^{40}$ y este es el sentido fundamental que tiene la afirmación de que la filosofía del Derecho es una filosofía práctica. El conjunto de ideas epistemológicas bajo las cuales la filosofía del Derecho analiza críticamente la racionalidad jurídica en términos argumentativos -ideas tales como "interpretación", “corrección", “lógica", "argumento", “verdad", "objetividad"...- revela la primacía de la dimensión justificativa de la práctica jurídica y su conexión interna con juicios de valor extrajurídicos de carácter moral y político y también epistémico. ${ }^{41}$

Por otro lado, las consecuencias ontológicas de lo anterior no apuntan sino a que la "realidad" o "ser" del Derecho es la de una empresa práctica que, anclada en un sistema político de autoridad, pretende simultáneamente dotarse de validez moral o justificación objetiva. Esto implica suministrar razones cuyo alcance desborda por fuerza la contingencia de cualquier "hecho" o fuente social, cualquier convención o ideología, para vincularse a valores que deben considerarse como ideas objetivas de alcance históricocultural. Estas ideas (que son centralmente los ideales de justicia y racionalidad constitutivos de la práctica argumentativa jurídica, ellos mismos en el origen de la propia dialéctica filosófica desde la Grecia clásica) demuestran que el "deber ser" del Derecho no 
puede desgajarse de su realidad o ser, sino que es interno a ésta, como lo son las concepciones sobre el mismo. Ello no sólo vuelve filosóficamente inconsistente a cualquier escepticismo axiológico o criticismo radical que, al reducir fácticamente los valores (como ideologías o hechos sociales, como simple disfraz de los mecanismos estratégicos de poder) pretenda negar la objetividad o validez de las razones valorativas del Derecho. También hace especialmente autofrustrante y ciego a la verdadera configuración práctica del Derecho al propio positivismo jurídico en la medida en que pretenda hacerse compatible (como "positivismo ético") con alguna clase de objetivismo moral. ${ }^{42}$ Ya que la tesis de la separación o segregación del Derecho respecto de los valores morales sería una tesis ella misma normativa o moral que se apoya sobre lo que pretende negar: que los valores morales no estén efectivamente presentes en el Derecho, sino que sean objetivamente constitutivos de éste. Éstos no podrían verse ya como valores meramente "conceptuales", epistémicos o atribuidos, sino como valores prácticos sustantivos. Esto presupone una concepción normativa de la teoría del Derecho y, por tanto, una comprensión de la filosofía jurídica como filosofía práctica.

Y de ahí, en definitiva, que el discurso de los valores jurídicos - la axiología jurídica- no pueda entenderse como un tercer discurso o parte de la filosofía del Derecho independiente del discurso sobre el concepto del Derecho (ontología jurídica) o sobre sus formas de conocimiento (epistemología jurídica), tal como es habitualmente entendido. Eso no sería, a fin de cuentas, sino un resabio de la visión positivista del Derecho. Y no sólo un resabio, sino también una rémora. Pues la concepción más coherente con la verdadera posición que el Derecho ocupa dentro del espacio político-moral precisamente por la centralidad que para él tienen los valores-, esto es, la concepción postpositivista que llamamos constitucionalismo o la visión argumentativa del Derecho, supone trascender ese planteamiento metódico avalorativo del positivismo para concebir la filosofía del Derecho como filosofía práctica integrada con la filosofía moral y política. La universalidad del concepto del Derecho o de su conocimiento (y, por tanto, la universalidad de la filosofía jurídica) no podría recluirse en ningún recinto categorial, como si se tratase de un concepto "natural", "criterial" o "semántico" (es decir, científico). La idea de construir un concepto universal del Derecho ha estado presente desde muy antiguo en la historia de la filosofía jurídica (desde el koinos nomos griego y el ius gentium romano hasta el Derecho natural medieval y el Derecho racional moderno o la teoría general del Derecho positivista), pero siempre ha sido en realidad un proyecto filosófico. El concepto del Derecho es un "concepto interpretativo" construido a partir de ideas y concepciones presentes en la práctica jurídica y en los conceptos doctrinales del Derecho metódicamente ligados a su punto de vista interno justificativo, a la prudentia iuris. $^{43}$ Lo verdaderamente universal en el Derecho serían entonces los valores mismos entendidos como ideas de vocación trascendental desde los cuales puede remontarse (totalizarse críticamente) el anclaje histórico contingente o particularista de tal práctica justificativa. La categoricidad de la instituciones y normas jurídicas es contextual, siempre fragmentada en círculos regionales idiográficos e idiorrítmicos (Estados nacionales, familias jurídicas, tradiciones culturales, etc.), dado que las normas, aunque objetos abstractos, son individuos en sentido lógico. Sólo los valores serían susceptibles de universalización cuando juegan su rol justificativo y aparecen así como las verdaderas ideas que hacen de la práctica jurídica una práctica racional, universalizable. En la medida en que esas ideas dejen de estar presentes en ella, perderá aquello que le presta verdaderamente racionalidad. Y en la medida en que la filosofía jurídica pretenda prescindir de ellas, para presentarse como más "técnica" o más "científica", pondrá en 
riesgo su propia pretensión de universalidad, que no es la de una filosofía teórica sino práctica.

-Agradecimientos. - Este trabajo forma parte del proyecto de investigación "Desarrollo de una concepción argumentativa del Derecho" (DER2013-42472-P) financiado por el Ministrerio de Economía y Competitividad del gobierno español.

\section{BIBLIOGRAFÍA}

Robert ALEXY, 2005: La institucionalización de la justicia. Trad. J.A. Seoane et al. Granada: Comares. ARISTOTLE, The Complete Works of Aristotle: The Revised Oxford Edition. Ed. J. Barnes, Princeton: Princeton University Press, 1995.

Manuel ATIENZA, 1989: Introducción al Derecho. Barcelona: Barcanova.

Manuel ATIENZA, 2013: Curso de argumentación jurídica. Madrid: Trotta.

Manuel ATIENZA, 2015: La filosofía del Derecho como filosofía 'regional'. URL: http:// lamiradadepeitho.blogspot.com.es y http://iusfilosofiamundolatino.ua.es (6 de Mayo 2017). Claudia BARACCHI, 2008: Aristotle's Ethics as First Philosophy. New York: Cambridge University Press.

Norberto BOBBIO, 1950: Interpretazioni anglosassoni della filosofia del diritto. Rivista internazionale di filosofia del diritto. 35 (1950) 1. 90-101.

Norberto BOBBIO, 1990a: Naturaleza y función de la Filosofía del Derecho [1962]. Contribución a la Teoría del Derecho. Ed. Alfonso Ruiz Miguel. Madrid: Debate. 91-101.

Norberto BOBBIO, 1990b: Filosofía del Derecho y Teoría General del Derecho [1950]. Contribución a la Teoría del Derecho. Ed. Alfonso Ruiz Miguel. Madrid: Debate. 73-90.

Gustavo BUENO, 1970: El papel de la filosofía en el conjunto del saber. Madrid: Ciencia Nueva.

Gustavo BUENO, 1999: ¿Qué es la filosofía? Oviedo: Pentalfa.

Roger COTTERRELL, 2014: Why Jurisprudence is not Legal Philosophy. Jurisprudence: An International Journal of Legal and Political Thought 5 (2014) 1. 41-55.

Elías DÍAZ, 1992: Sociología y Filosofía del Derecho [1971]. Madrid: Taurus.

Ronald DWORKIN, 1986: Law's Empire. Cambridge, Mass.: Harvard University Press.

Ronald DWORKIN, 2006: Justice in Robes, Cambridge, Mass.: Harvard University Press.

Ronald DWORKIN, 2010: ¿Deben nuestros jueces ser filósofos? ¿Pueden ser filósofos? Isonomía 32 (2010). 7-29 (trad. L. García Jaramillo).

Luigi FERRAJOLI, 2008: La Teoría del Derecho en el sistema de los saberes jurídicos. La Teoría del Derecho en el paradigma constitucional. Eds. Luigi Ferrajoli, José Juan Moreso and Manuel Atienza. Madrid: Fundación Coloquio Jurídico Europeo. 25-69.

Riccardo GUASTINI, 2011: La sintassi del diritto. Turín: Giappichelli. 
Herbert L. A. HART, 1987: Comment. Issues in Contemporary Legal Philosophy. Ed. R. Gavison. Oxford: Clarendon Press. 35-42.

Werner JAEGER, 1982: Alabanza de la ley. Los orígenes de la filosofía del Derecho y los griegos [1947]. Trad. A. Truyol. Madrid: Centro de Estudios Constitucionales.

Werner JAEGER, 2001: Paideia. Los ideales de la cultura griega [1933]. Trad. J. Xiral. México: FCE. Vol. I.

Immanuel KANT, 1968a: Die Metaphysik der Sitten [1797]. Kants Werke Akademie-Textausgabe. Berlín: Walter de Gruyter \& Co. 1968. Vol. VI. 203-494.

Immanuel KANT, 1968b: Der Streit der Facultäten [1798]. Kants Werke Akademie-Textausgabe. Berlín: Walter de Gruyter \& Co. 1968. Vol. VII. 1-113.

Hans KELSEN, 1962: Qu'est-ce que la Philosophie du Droit?. Archives de Philosophie du Droit 7 (1962). 131.

Andrei MARMOR, 2011: Philosophy of Law. Princeton: Princeton University Press.

Thomas NAGEL, 2000: La última palabra. La razón ante el relativismo y el subjetivismo. Barcelona: Gedisa.

Carlos Santiago NINO, 1994: Derecho, moral y política. Barcelona: Ariel.

Michael OAKESHOTT, 2007: The Concept of a Philosophical Jurisprudence [1938]. The Concept of a Philosophical Jurisprudence: Essays and Reviews 1926-51. [Selected Writings. Vol. III]. Ed. L. O'Sullivan, Exeter: Imprint Academic. 154-183.

Gerald POSTEMA, 1998: Jurisprudence as Practical Philosophy. Legal Theory 4 (1998). 329-357. Gerald POSTEMA, 2015: Jurisprudence, the Sociable Science. Virginia Law Review 101 (2015) 4. 869-901.

Roscoe POUND, 2002: The Ideal Element in Law [1958]. Indianapolis: Liberty Fund, Inc.

John RAWLS, 1993: Political Liberalism. New York: Columbia University Press.

John RAWLS, 1994: La idea de una razón pública. Isegoría 9 (1994). 5-40 (trad. A. Domenech).

Josep RAZ, 1990: Practical Reason and Norms. New York: Oxford University Press.

Josep RAZ, 1995: Ethics in the Public Domain. Essays in the Morality of Law and Politics. Oxford: Clarendon Press.

Josep RAZ, 2009: Between Authority and Interpretation. On the Theory of Law and Practical Reason. New York: Oxford University Press.

Alf ROSS, 1959: On Law and Justice. Berkeley: University of California Press.

Manuel SACRISTÁN, 1968: Sobre el lugar de la Filosofía en los estudios superiores. Barcelona: Nova Terra.

Amartya SEN, 2009: The Idea of Justice. Cambridge, Mass.: Harvard University Press.

Jean-Paul VERNANT, 1985: Mito y pensamiento en la Grecia antigua [1965]. Trad. J. López. Barcelona: Ariel.

Theodor VIEHWEG, 1991: La Filosofía del Derecho como investigación básica [1961]. Tópica y Filosofía del Derecho. Trad. J. M. Seña. Barcelona: Gedisa. 29-51.

Jeremy WALDRON, 1994: Vagueness in Law and Language: Some Philosophical Issues. California Law Review 82 (1994) 3. 509-540. 
Jeremy WALDRON, 2010: Normative (or Ethical) Positivism. Hart's Postscript. Essays on the Postscript to The Concept of Law. Ed. Jules Coleman. Oxford: Oxford University Press. 410-433.

\section{NOTAS}

1. Atienza 1989: 371; véase también Díaz 1992: 334, 369.

2. Bueno 1970; 1999.

3. La "trascendentalidad" tendría entonces un sentido no apriorístico o metafísico (como sucede en el propio Kant) sino relativo a la recurrencia a posteriori de la racionalidad práctica humana en sus diferentes contextos categoriales (Bueno 1970; 1999). Una perspectiva similar en Nagel 2000.

4. "En mi opinión no hay principios definidos que determinen el dominio de la filosofía del derecho; no hay criterios internos que señalen dónde concluye la ciencia del derecho y dónde comienza la filosofía jurídica" (Ross 1994: XIV).

5. "Se entiende que la preferencia hacia las obras de los juristas que se elevan a la filosofía más que hacia las de los filósofos que se rebajan hasta el mundo del Derecho, revela la preferencia por un método, o mejor, por un cierto estilo de trabajo, que es más fácil encontrar en las obras de los primeros que en las de los segundos: lo que caracteriza a este estilo de trabajo es la primacía dada al análisis sobre la síntesis, primacía fundada en la convicción de que, aun siendo análisis y síntesis momentos necesarios de toda investigación, es siempre preferible un análisis sin síntesis (lo que se les reprocha a menudo a los juristas-filósofos) que una síntesis sin análisis (que es el vicio común a los filósofos-juristas), al procurar el primero al menos buenos materiales para construir y al construir la segunda casas de arena a las que nadie iría a vivir de buena gana" (Bobbio 1990: 96).

6. El argumento central de Bobbio es que la filosofía del Derecho de los juristas, aun pudiendo ser más analítica que sintética y de aspiraciones filosóficas no rigurosamente sistemáticas, sería una reflexión elaborada sobre materiales empíricos, positivos, justamente por provenir de juristas que trabajan "a pie de obra" del Derecho, mientras que la filosofía del Derecho de los filósofos sería eminentemente una filosofía dogmática, apriorística, una "filosofía aplicada" de sistemas y doctrinas extrínsecas al campo del Derecho en la que los problemas generales del Derecho no son estudiados partiendo del trato con la experiencia jurídica sino desde esos sistemas previos dando lugar así a construcciones especulativas ("castillos en la arena") que justifica plenamente los recelos tradicionales del jurista hacia la filosofía.

7. Las expresiones son de Cotterrell 2014.

8. Que la filosofía de juristas a la que Bobbio se adscribe es básicamente la vinculada al positivismo jurídico se desprende de los nombres mencionados por él (Hobbes, Ihering, Gény, Ehrlich, Kelsen, Kantorowicz, Ross, Hart), mientras que prototipos de filosofía de filósofos ("aplicada") que cita son el tomismo o el hegelianismo. Como es sabido, Bobbio estuvo muy influido por el positivismo lógico en su comprensión de las relaciones entre ciencia y filosofía. Por lo demás, su adversario directo en el citado texto de 1962 -y esto explica su intención polémica y antimetafísica- es el iusfilósofo hegeliano G. Gentile, “ejemplo límite de radicalización e hipostatización filosófica" (Bobbio, 1990: 96).

9. Una tripartición similar puede encontrarse en Oakeshott 2008 cuando habla de la filosofía jurídica como applied philosophy, como a priori natural law y como philosophy of jurisprudence. A ellas se opondría la verdadera philosophical jurisprudence.

10. Hay incluso quien ha criticado a la filosofía iuspositivista de orientación analítica como "escolástica" (Dworkin, 2006: 213) o ha denunciado su alejamiento de los intereses prácticos de la jurisprudence (Cotterrell, 2014; Postema, 2015). Es decir, los mismos atributos descalificatorios que Bobbio dirige a la iusfilosofía "de filósofos". 
11. Kant, I., Der Streit der Fakultäten, I, 3 [1798; 1968: 28].

12. Por 'filosofía dogmática' cabe entender toda aquella que se concibe a sí misma como un saber no reflexivo-secundario sino originario, radical o de primer grado, un tipo de saber sustantivo y previo que no se alimentaría de fuentes situadas más allá de sí mismo sino que más bien se “ aplica" descendentemente, como sistema de "verdades", sobre contenidos o materias que en sí son meramente posteriores y secundarios (una "función general" que se realiza o verifica ex post en "variables" monótonas). Filosofía dogmática es toda filosofía puramente academicista o profesoral que se autopresenta como una doctrina cerrada y acabada y pretende fundarse en principios intemporales o ahistóricos, no inserta en el presente histórico, práctico y científico sino consistente en verdades fundamentalmente exentas respecto de las realidades categoriales, situada por encima o independientemente de las mismas como una philosophia perennis.

13. Así se comprueba, por ejemplo, a propósito de la distinción entre "concepto" y "naturaleza" del Derecho (Raz 1995: 195ss.; 2009: 17ss., 91ss.).

14. Kant, I., Die Metaphysik der Sitten, "Einleitung in die Rechtslehre”, § B [1797; 1968, 229-230].

15. La constitución de la filosofía clásica griega está estrechamente vinculada con la discusión de los filósofos frente a sofistas, oradores y políticos en torno al concepto de Derecho (nomos) y los ideales de justicia (dike, dikaiosyne, to dikaion). De esta discusión arrancan no solo la lógica, la dialéctica y la retórica, dentro del contexto de la democracia de la polis, basada en la técnica discursiva del logos como razón pública (isegoria, isonomia), sino en realidad la entera filosofía ética y política de Platón y Aristóteles. Véase, p. ej., Jaeger 2001: 97ss.; 1982. De ahí que la filosofía práctica sea la verdadera "filosofía primera" (Baracchi, 2008). Pero también se halla profundamente conectada con la segunda fuente principal de la que surge la filosofía -la aparición del saber científico universal matemático-, puesto que la concepción geométrica del cosmos persigue, por decirlo con Vernant, "una racionalización de las relaciones políticas que busca "menos poner a la polis en armonía con el sagrado orden del universo que lograr precisos fines políticos" (Vernant, 1985: 193ss., 356). Una combinación similar de filosofía práctica y racionalismo científico se repetirá en la filosofía moderna e ilustrada en el contexto de la formación del Estado moderno.

16. Cf. Viehweg 1991: 35, 44ss.

17. El mismo Bobbio asume esto cuando, al final del texto que hemos venido citando, remite la oposición entre filosofía del Derecho de juristas y filósofos a una opción filosófica de carácter último ("una diferencia más profunda entre dos modos de filosofar") que debe elegir ante los dilemas monismo/pluralismo o racionalismo/empirismo (Bobbio 1990: 98), siendo los juristas más propensos al segundo cuerno de estas dicotomías, ya que como se dijo dan prioridad al análisis sobre la síntesis. Es preciso notar, sin embargo, que para Bobbio esto no implica necesariamente una fragmentación analítica nítida de la filosofía jurídica en las tres subdisciplinas especiales que él distingue (teoría del Derecho, teoría de la ciencia jurídica y teoría de la justicia). En el último párrafo de su artículo afirma, en efecto, que una "disciplina unitaria" es la mejor forma en que la filosofía jurídica puede cumplir su papel práctico y crítico (un papel, por cierto, muy próximo a lo que llamamos "totalización crítica"): “[L]a tarea de la filosofía del Derecho, desde el punto de vista didáctico, es la de romper los diques que mantienen a las disciplinas jurídicas tradicionales en el embalse artificial de un sistema positivo. Este objetivo puede ser mejor cumplido minando la presa por varias partes a la vez" (Bobbio 1990a: 99).

18. Pound 2002: 30ss., passim.

19. Como es sabido, las ideas de la razón práctica en Kant tienen en relación con los conceptos un uso constitutivo o "categórico" y no regulativo, en su función de prestarles unidad o totalidad.

20. Alexy 2005: 45ff.

21. Cf. Waldron 1994: 527ss.

22. Raz 1991: 232. 
23. Dworkin 2006: 35.

24. Atienza 2013: 284

25. Ética a Nicómaco, V.

26. Rawls 1994: 19ss.

27. Dworkin 1986: 404ss.

28. Sen 2009.

29. Nino 1994

30. Sobre la "primacía lógica del punto de vista interno de la práctica humana", véase Nino 1994:

$37,47$.

31. Kelsen 1962: 131.

32. Hart 1987: 37ss

33. Una clara y temprana formulación de ambas tesis puede encontrarse en Bobbio 1990b. La Teoría general del Derecho, dice Bobbio ahí, es fáctica, formal, científica, no filosófica y se ocupa exclusivamente del concepto del Derecho, mientras que la filosofía del Derecho es evaluativa, material, y confinada a la idea de justicia como una cuestión de valor o de toma de posición ideológica. "Filosofía del Derecho en sentido propio sólo lo es la teoría de la justicia" (Bobbio 1950: 96).

34. Ferrajoli 2008: 28ss., 45, 49ss.

35. Guastini 2011: 7ss., 9.

36. Raz 1995: 235ss.

37. Marmor 2011: 129ss.

38. Idea filosóficamente reconocida desde la epieikeia de Aristóteles a la open texture de Hart.

39. Ferrajoli 2008: 57ss.

40. Postema 1998.

41. Sobre la prioridad de la perspectiva material (esto es, valorativa) de la argumentación jurídica sobre la formal (lógica) y pragmática (dialéctica y retórica), vease Atienza 2013.

42. Waldron 2001.

43. Quien mejor ha comprendido este punto es, sin duda, Dworkin, cuando afirma que los jueces constitucionales toman decisiones filosóficas no sólo ocasionalmente, ante un caso difícil particular (esto es, aquel que cuestiona los fundamentos valorativos del Derecho establecido), sino como cuestión de rutina, dado que los conceptos que emplean en sus decisiones ("responsabilidad, significado, intención, igualdad, libertad y democracia, por ejemplo") son "conceptos difíciles" - esto es: ideas- que requieren desplegar una práctica reflexiva y argumentativa sobre algunos de los más complejos asuntos de la moralidad política (esto es: articular concepciones sobre los valores prácticos fundamentales) (Dworkin 2010: 22, 29, 33).

\section{RESÚMENES}

El propósito del presente trabajo es argumentar a favor de la naturaleza estrictamente filosófica de nuestra disciplina, la filosofía del Derecho. Parto, para ello, de un planteamiento previo acerca de la cuestión de qué es en general la filosofía, introduciendo unas premisas mínimas para la definición de la racionalidad filosófica. Esto me lleva a reconsiderar críticamente, en segundo lugar, la célebre dicotomía de Bobbio entre "filosofía del Derecho de los juristas" y "filosofía del Derecho de los filósofos". El tercer punto que abordo es reconsiderar las relaciones existentes 
entre la filosofía jurídica como disciplina "especial" o "regional" y la filosofía "general", para lo cual utilizo la distinción entre conceptos e ideas del Derecho. En cuarto lugar, desarrollo la idea de que lo decisivo a la hora de entender qué tipo de filosofía es la filosofía del Derecho no es tanto (o no sólo) la relación que media entre ella y la filosofía en general cuanto, sobre todo, la relación que media entre ella y el propio Derecho. Sostengo así, en quinto lugar, que es el tipo de práctica que el Derecho constituye lo que convierte en necesaria su vinculación interna e ineludible con ideas y concepciones de naturaleza filosófica. Esta visión práctica del Derecho es íntimamente solidaria de una visión de la filosofía jurídica como filosofía práctica, diferentes expresiones de la cual pueden hallarse en autores contemporáneos de gran relevancia que de distintos modos se han situado más allá de la dicotomía iuspositivismo-iusnaturalismo (tales como Nino, Alexy, Dworkin o Atienza), y que sería entonces (sexto y último punto) la tesis central que aquí defiendo. El rasgo esencial que considero unido a tal condición -la de constituir un tipo de "filosofía práctica"- es la centralidad y preeminencia que en ella adquiere la dimensión valorativa.

ÍNDICE

Palabras claves: filosofía del Derecho, filosofía práctica, positivismo jurídico, teoría del Derecho, post-positivismo jurídico

\section{AUTOR}

\section{JESÚS VEGA}

Universidad de Alicante (Spain)

E-mail: jesus.vega@ua.es 